\title{
The Effectiveness of Social Media Application "Telegram Messenger" in Improving Students' Reading Skills: A Case Study of EFL Learners at Ajloun University College/Jordan
}

\author{
Muntaha Ali Mohammad Al Momani \\ Department of English, Ajloun University College, Al Balqa Applied University, Jordan
}

\begin{abstract}
With the advent of smart phones and new smart devices, the use of these mobile communication devices has become an integral part of our daily life. The study aims to discuss the influence of modern technological apps in developing students' skills such as telegram messenger channels on improving reading skills E-leaning, m-learning and techno-aids might help to fill the gap. The study is conducted on EFL learners at Ajloun University College. To sum up, the study has provided evidence to the effectiveness of Telegram ${ }^{\circledR}$ social media application in improving students' reading skills.
\end{abstract}

Index Terms-English as a Foreign Language, reading skills, smart phones role in education, social media applications, Telegram Messenger

\section{INTRODUCTION}

Nowadays, the world is in the era of social media revolution, the age of smart phones and smart devices applications. We use phone devices not only for communications with others, but for a variety of other purposes, as well. Actually, with the advent of smart phones and new smart devices, the use of these mobile communication devices has become an integral part of our daily life. Today, people from all ages have the ability to use smart devices applications, including young students anytime anywhere (Cook \& Das, 2007).

The students prefer the utilization of their mobile devices to access the internet and conduct learning related activities. (Wong, 2015)

The new generation of young students has technical, electronic and digital minds. They deal with the new technology as a piece of cake. In fact, they are fully aware of the globalization and part of it (Bolstad, \& Gilbert, 2006). They spend most of their time working on their smart phones. By time, such students lose enthusiasm to learn from regular books and traditional curriculums with the prevalence of the social media, the smart phones and smart devices applications. However, over a period, these mobile apps are playing significant role in the day-to-day lives including education. These phone applications have made our life simpler and have provided yet another innovative way of accessing education. In fact, "these profound changes are placing increasing pressure on the traditional models of teaching and learning."( Bansal \& Dhananjay Joshi, 2014). Thus, our students deserve better when it comes to education. E-leaning, m-learning and techno-aids might help to fill the gap. Actually, there is a shift to e-learning that is enabled by communication technologies (Campbell, 2010).

In fact, the world has seen a steady and rapid increase in the growth of phone applications, since the appearance of the Apple App Store in 2008. Varieties of smart phones applications are currently available. However, among the top lists in the popular applications given by various sources, a prominent name that is emerging all over the globe is Telegram. Telegram messenger is a mobile application that has apparently caught the attention of large number of mobile users (Giordanoet al, 2015).

Mobile assisted learning (MALL) can be defined as the use of small, portable, wireless devices such as mobile phones, smartphones and personal computers to achieve flexibility and interaction in teaching and learning anytime and anywhere (Mehmadi, 2012).

Digital devices, mobile phones and Tablet PCs can be used to perform many educational tasks, although their role differ. Most mobile devices are useful in teaching, facilitating teachers' tasks and considered as learning aids for students as illustrated by the following (Kasem et al., 2006):

Students can interact with each other and with the teacher instead of hiding behind the large monitor.

- Many portable devices in the classroom are easy to be installed compared to desktops that require a lot of space.

Most personal digital devices, notebooks, tablets, and smart phones are lighter, smaller and easier to carry than bags filled with files, books or any paper study material.

Handwriting recognition applications in personal portable devices help in improving students' handwriting 
skills.

- Increase motivation and personal commitment to learning if the student will take the device home at any time he wants, it helps him to commit and take responsibility.

- $\quad$ Attract learners: young people who have dropped out of education can enjoy the use of mobile devices.

Mobile assisted learning could help the English language teachers by saving time through enabling them to transmit educational information to the class students in an effective manner.

Regarding the classroom activities, teachers could utilize the mobile applications to explain the English language grammatical rules which will be more effective than writing the rules on the blackboard (Dajani and Wahba, 2001).

The introduction of mobile assisted learning in teaching English language in the private and public schools in the Kingdom of Saudi Arabia could be useful. Therefore, the integration of educational technologies in the schools is probably a very important issue of concern to the policy makers in the Saudi ministry of education (Mehmadi, 2012).

Telegram messenger is a cloud-based mobile and desktop messaging application with a focus on security and speed which was launched on August 14, 2013 to make communication and the distribution of multimedia messaging more easily and faster. "Telegram Messenger is a messaging application focusing on instant and secure messaging, it's superfast, simple and free. Individuals can download Telegram on all portable devices at the same time- and synchronize their conversations seamlessly across any number of your devices." (Telegram®.com, 2017).

Nowadays, millions of people are using Telegram. That's nearly one in seven people in the world who use Telegram monthly to keep connected with their loved ones, friends and family.( Telegram Blog, 2017). Telegram is supported financially and ideologically by Pavel and technological by Nikolai Durov.

Using Telegram messenger in English language learning had positively affected the students' comprehension of vocabulary and grammatical rules (Alkhezzi \& Al-Dosari, 2016)

Since Telegram is relatively a new phenomenon, little research exists regarding its influence on interpersonal communication in general, and between high school teachers and their students in particular (Church \& de Oliveira, 2013). While reviewing the literature of the topic of this study, few references and books were found tackling the issue of Telegram messenger from the pedagogical perspective. Most of the information found was in the form of articles, researches, or thesis. Most of the writers' arguments of these works lead to the recommendation to adopting Telegram as a perfect educational assistant. Yet, on the other hand, there are others who have not the same attitude towards the application.

\section{REVIEW OF RELATED LITERATURE}

Here is a review of the views of some of the writers who recommend using Telegram as an effective and successful teaching-learning aid as well as others of the contrasted team.

Digital communication between groups of students and between students and teachers has become popular during the last decade through various channels: Email, SMS, Facebook groups, Twitter, Whatsapp and recently Telegram. Each one of these tools has different characteristics that influence its suitability for learning purposes. (Calvo, Arbiol and Iglesias, 2014).

Previous studies examined different use of Telegram in educational settings. One study investigated the effectiveness of using Telegram in teaching English pronunciation to Iranian EFL learners. Study participants had included 30 Iranian EFL learners divided into an experimental group $(\mathrm{N}=14)$ and a control group $(\mathrm{N}=16)$. Study groups had received various treatments over a period of 4 weeks. Study findings for the pre and posttest had indicated that there is a significant improvement in the pronunciation of participants in the experimental group compared to the control group. Study had concluded that utilizing Telegram messenger in teaching English language is an effective and promising approach (Xodabande, 2017).

In a study conducted by Zarei et al (2017) that aimed to investigate the impact of using Telegram on EFL learners' and the knowledge and attitudes of them towards vocabulary learning. Study sample had been composed of $100 \mathrm{EFL}$ learners that were involved in a quasi-experimental study. Participants were divided into two study groups; the control group $(\mathrm{N}=50)$ and the experimental group $(\mathrm{N}=50)$. Both group members had received a three weeks vocabulary instruction. Experimental group members had been asked to fill out a pre-designed questionnaire. Finally, a vocabulary test had been administered among the participants of the both groups. Study findings had shown that there is a significant outperformance of the experimental group over the control group. Furthermore, study findings had shown that the study participants had positive attitudes toward using Telegram messenger.

Many studies had investigated the impact of similar mobile applications such as Whatsapp on the learning outcomes. For instance, a study conducted by Bansal et al(2014) aimed to investigate students' experiences of Whatsapp ${ }^{\circledR}$ mobile learning, during session 2013-2014, and examined a sample of 37 Bachelor of Education students. Study sample students and their teacher were interacting with each other within Whatsapp ${ }^{\circledR}$ group and finally students were asked to fill in a pre-designed questionnaire. Findings of the study had showed an increase in students' social interactivity and they learned collaboratively, as well as Whatsapp ${ }^{\circledR}$ was favorable for students. Moreover, study results indicated that married students considered that learning using Whatsapp ${ }^{\circledR}$ is disruptive and they prefer traditional classroom learning.

\section{OBJeCtIVES OF THE STUDY}


As a teacher of English for years, the researcher realized that learning has changed from a mere repetition and memorization of facts to interactive strategies of learning. This study is conducted for three main reasons. Firstly, to have students and teachers get out of the monotonous and boring class atmosphere and to experience other live interactive atmosphere, whether inside or outside the classroom . Secondly, to identify the impact of using Telegram as a mobile learning tool on reading skills of undergraduate EFL learners at Ajloun University College. This study will go through new teaching-learning methods that are more appropriate and suitable for students' interests and preferences so as to provoke their awareness towards the content being learned.

\section{PRoblem of THE StUdy}

This study came to address two major problems. Mainly, formal learning that is widespread in our schools does not allow the design of authentic learning tasks. Also, mobile phones are hardly used for teaching and learning in the learning settings. Moreover, though our students become so fond of their smart phones to the extent that they cannot live without. Thus, it becomes a must for us to adopt new techniques including mobile apps. Telegram, as a very popular social media application among students, may solve the problem.

\section{RESEARCH QUESTIONS}

This study is conducted mainly to answer the following major question:

Are there any significant statistical differences at significance level $(\alpha \leq 0.05)$ between the Control group and the experimental group in the reading post-test referred to using Telegram Messenger channels?

\section{SigNIFICANCE OF THE STUDY}

This study is considered important as follows

1. Theoretical significance: current study will provide good literature regarding the impact of using Telegram messenger channels on English language learners' reading skills.

2. Practical significance:

- $\quad$ For teachers and instructors: it will provide a new educational method that will improve students' reading skills.

For college administration: The findings of the current study will enable the administrative authorities and decision makers in the educational institutions to have a reference for the formulation of the educational policies.

\section{Methodology}

This study is designed to investigate the impact of Telegram messenger channels usage on improving reading skills of undergraduate EFL learners in Ajloun College University.

Setting: A quasi-experimental approach that is represented by a pre and post-test over two students groups (An experimental group and a control group) will be adopted in this study.

Population and sampling: The population in the current study was the 2nd year Jordanian EFL learners registered as regular students in Ajloun University College following Al-Balqa'a applied university, and enrolled in the reading skills course in the first semester of the academic year 2019/2020.

Purposeful sampling was performed to get the study sample; the researcher intentionally selected two classes to represent the study sample. Each class consisted of 35 students. Class A represented the control group whereas the Class B represented the experimental group.

Data collection tools

The researcher designed the reading skills' test that was used in this study as an assessment tool for participants' reading skills. The reading skills test was designed through identifying the objectives of the test and analyzing the content of the teaching material presented in the reading curriculum studied by 2nd year EFL learners. Briefly, the researcher followed the following procedure in constructing the reading pre/posttest before releasing it in the final form:

Determining the general aim of the test: As this test aims at measuring the level of reading skills of the $2 \mathrm{nd}$ year undergraduate EFL learners in Ajloun College University.

- $\quad$ Reviewing the literature and previous local and international studies that investigated the reading skills of the EFL learners. The purpose of this step was to get use of the standard procedure of constructing a reading skills pre and post-test.

- $\quad$ Analyzing the content of the teaching material presented in the reading curriculum that is studied by 2 nd year EFL learners in Ajloun University College. This was performed in order to set the description of the test and determine the items of the test.

- $\quad$ Setting the instructions of the test: The researcher prepared the instructions of the test that included the aim of the reading test, the number of items, and the time allotted to answer the test items.

- Preparation of the first version of the reading skills test: after determining the reading skills that were needed 
to be improved among 2nd year EFL learners at Ajloun University College, the researcher constructed the first version of the reading pre/post-test. The first version consisted of one reading passage with 20 items

- Validating the reading test: the researcher submitted the reading test to a panel of jury members who were asked kindly to review the reading test in terms of the clarity of the language, the comprehensiveness of the test items and to provide any useful comments that might improve the reading test.

- $\quad$ Measuring the reliability of the test: To ensure the reliability of the test, the researcher used the test-retest method by administering the reading test on a pilot sample consisted of 20 EFL learners with a time interval between the first and second administration of two weeks. Pearson's correlation factor was calculated to be (0.91) which is acceptable in educational research.

\section{PRocedure FOR THE EXPERIMENTAL AND CONTROL GRouP}

Participants of the experimental group were required to provide the researcher with their phone numbers. Then, they were trained to run the application on their smart phones and joined the online learning group.

Previous procedure was performed to make the students familiar with the outline group and things they needed to be involved in the learning process.

Before proceeding in the study, the researcher had held an introductory session for the experimental group to give a brief summary about the study and its benefits to the teaching and learning processes.

Data collection procedure had started, it had been performed over a period of four weeks (15 sessions including the introductory session). Students had attended their classes and committed to follow the normal activities of the class.

Each online learning session had included posting the studied lessons' vocabularies and reading exercises. Posted data could be reviewed by the group members.

Thus, the experimental group members had been involved in one hour traditional class at the college, three online sessions weekly on Mondays, Wednesdays, and Thursdays. Furthermore, the online participation was not restricted to a specific time, students could post their questions to be answered by the teacher.

After 14 sessions of using Telegram online learning environment, study participants had been tested for their reading skills.

On the other hand, participants of the control group had received a traditional learning in the classroom context.

\section{Data AnAlysis}

Data from the pre and post reading tests were be compiled, sorted, coded and imported to Excel sheets , and finally calculated using Statistical Package for Social Sciences (SPSS) in order to perform the statistical analysis such as frequencies, mean, standard deviation, and correlation coefficients analysis . Independent samples t-test and One Way ANOVA were used to identify the differences in reading performance among the control and the experimental groups.

\section{RESUlts AND DiscusSiON}

The current study aimed at investigating the impact of using Telegram messenger channels on improving reading skills among 2nd year EFL learners at Ajloun University College.

Means and standard deviations of the study participants in reading pre and post-test were calculated for both study groups (the experimental and the control).

It is obvious from table (1) that there are apparent differences between the mean scores of the participants in reading pre and post-test based on the study group (experimental and control).

TABLE (1):

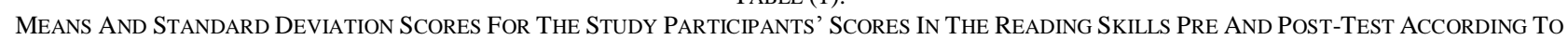
THE GROUP (EXPERIMENTAL AND CONTROL)

\begin{tabular}{llllll}
\hline Post test & \multicolumn{5}{c}{} \\
\hline $\begin{array}{l}\text { Standard } \\
\text { deviation }\end{array}$ & Mean & $\begin{array}{l}\text { Standard } \\
\text { deviation }\end{array}$ & Mean & $\mathrm{N}$ & Group \\
\hline 1.006 & 17.20 & 2.013 & 13.69 & 35 & Experimental \\
1.740 & 13.93 & 2.106 & 13.85 & 35 & Control \\
\hline 1.373 & 15.56 & 2.059 & 13.77 & 70 & Total \\
\hline
\end{tabular}

To identify in favor of which group these differences are referred, the researcher used One Way ANCOVA test after neutralizing the pre-test measurements for the groups.

Table (2) shows that there are significant statistical differences at significance level $(\alpha \leq 0.05)$ in the scores of the study participants in the reading test according to the study group (experimental and control), the $\mathrm{F}$ value was 93.068 with a significance value (0.000), which is statistically significant, and this revealed the effect of the study group. 
TABLE (2):

One Way ANCOVA Test Results For The ReAding Skills Post-Test ACCORding To The Study Group (ExPERIMENTAL, Control) After

\begin{tabular}{llllllll}
\hline $\begin{array}{l}\text { Eta } \\
\eta 2\end{array}$ & square & Sig & F value & $\begin{array}{l}\text { Mean of } \\
\text { squares }\end{array}$ & $\begin{array}{l}\text { Fum } \\
\text { degree }\end{array}$ & $\begin{array}{l}\text { Sum } \\
\text { squares }\end{array}$ & of \\
\hline .141 & .000 & 15.828 & 35.421 & 1 & 35.421 & Pariation source measurement \\
.561 & .000 & 93.068 & 223.408 & 1 & 223.408 & Group \\
& & & 2.489 & 67 & 204.461 & Error \\
& & & 69 & 475.826 & Total \\
\hline
\end{tabular}

In addition, it is clear that the teaching method effect was large, the Eta square value that was $56.1 \%$ explained the predicted variation in the dependent variable that is the reading skills test.

Estimated means and estimated standard errors were calculated for the study group in order to determine the direction of the significant differences (Table 3)

TABLE (3):

Estimated MEANS AND Estimated StANDARD ERRORS FOR THE READING SKILls ACCORDING TO THE STUDY GROUP (EXPERIMENTAL, CONTROL)

\begin{tabular}{lll}
\hline Modified standard error & Modified Post mean score & Group \\
\hline .235 & 17.20 & Experimental \\
.246 & 13.93 & Control \\
\hline
\end{tabular}

The results shown in table (3) indicated that the significant differences were in favor of the experimental group members that were exposed to Telegram messenger channels compared to the control group members who were instructed traditionally.

The previously presented results are attributed to the Telegram social audio platform that enables learners to receive lessons via text or voice messages, as well as the possibility of uploading videos and photos, which in turn reduces the direct communication between the teacher and the learner as in the classroom, which reduces the degree of learning anxiety of English learners. In addition, the services provided by the social networking platform (Telegram) allow the learner to participate actively in the discussions that take place between the teacher and other colleagues, which in turn contributes to the development of linguistic wealth of students and thus reflected positively on their language skills, especially reading skill. This result may also be attributed to the presence of direct feedback, and immediate individual and group guidance during the learning process, because untargeted repetition of the material leads to fixation in the mind of the learner, and the learning environment in which audio-visual methods are used in the Telegram platform may be stimulating, Especially for students who are ashamed of the classroom.

\section{CONCLUSION}

In conclusion, the study has provided an evidence to the effectiveness of Telegram ${ }^{\circledR}$ social media application in improving students' reading skills due to the different services it provides, such as the ability to introduce audio-visual topic explanation, besides to motivating students to search for knowledge and information independently, which points out to the key role of Telegram ${ }^{\circledR}$ application in creating a student-centered educational environment that is compatible with the modern learning theories that concentrate on the importance of students motivation and activation of students role to participate in an effective educational process to achieve the desired outcomes .

\section{SUGGESTIONS FOR FURTHER RESEARCH}

Based on the findings and the limitations of this study, I recommend the following suggestions for further research

1. To include various educational stages in the upcoming studies in order to cover wider slice of the educational environment elements.

2. Extend the study geographical borders, which will help harvesting more accurate and general findings.

3. Investigate the effect of various demographic factors such as gender, age, parents' educational level, etc.

4. Perform studies that include the implementation of a guidance activity of how to utilize social media tools in the educational process.

5. Involve the familiar learning approaches and theories along with the investigation of social media tools such as implementing a cooperative learning approach based on the usage of Telegram ${ }^{\circledR}$ application in the learning process, and application of constructivism theory concepts in the learning process.

\section{APPENDIX}

Cloze Test

A can't be

B must be

C will be

D was

18- I often get ..watching TV because the programmers are so boring.
A sleep
B sleepy
C sleeping
D asleep

19- What are you doing? I'm .............this man talking about Modern art. 

A listen
B hearing ..the speed limit.
20- The driver was fined for having
C listening to
D hearing from
A exceeded
B excessive
C excess
D excessively

\section{REFERENCES}

[1] Aldosari, H. (2016). Effects of integrating reading and writing during the reading process on EFL English writing in a Saudi college course: a quasi-experimental study. In First International Forum on Academic Teaching: Social Inclusion and Information and Communication Technology, 3rd to 5th October.

[2] Alkhezzi, F., \& Al-Dousari, W. (2016). The Impact of Mobile Learning on ESP Learners' Performance. Journal of Educators Online, 13(2), 73-101.

[3] Bansal, D., \&Dhananjay Joshi, T. (2014). A Study of Students Experiences of Whats App Mobile Learning. Global Journal of Human-Social Science Research, 14(4), 18-36.

[4] Bolstad, R., \& Gilbert, J. (2006). Creating digital age learners through school ICT projects: What can the Tech Angels project teach us. Education Counts, 13 (4), 31-52.

[5] Calvo, R., Arbiol, A., \& Iglesias, A. (2014). Are all Chats suitable for learning purposes? A study of the required characteristics. Procedia Computer Science, 27, 251-260.

[6] Campbell, S. W., \&Kwak, N. (2010). Mobile communication and civic life: Linking patterns of use to civic and political engagement. Journal of communication, 60(3), 536-555.

[7] Church, K., \& de Oliveira, R. (2013, August). What's up with whats app?: comparing mobile instant messaging behaviors with traditional SMS. In Proceedings of the 15th international conference on Human-computer interaction with mobile devices and services (pp. 352-361). ACM.

[8] Cook, D. J., \& Das, S. K. (2007). How smart are our environments? An updated look at the state of the art. Pervasive and mobile computing, 3(2), 53-73.

[9] Dajani, D. \& Wahba, N. (2001). The difficulties that hinder the use of the Internet as an educational tool in Palestinian schools. Paper presented at the Educational Process in the Internet Age, Palestinian. Journal of Educational sciences, 14(1), 15-28.

[10] Giordano, V., Koch, H. A., Mendes, C. H., Bergamin, A., de Souza, F. S., \& do Amaral, N. P. (2015). Whats App messenger is useful and reproducible in the assessment of tibial plateau fractures: Inter-and intra-observer agreement study. International journal of medical informatics, 84(2), 141-148.

[11] Kassem, M., Zeinab, A. \& Liz, E. (2006). Handbook for Arabic language teaching professionals in the 21st century (pp. 4, 241, 242, 244 \& 295-299). Mahwah, New Jersey: Lawrence Erlbaum.

[12] Mehmadi, R. (2012). The levels of Arabic language female teachers ability in efficiencies of elearning to teach it in a high school in the Holy Capital. (Unpublished Master Thesis), Umm Al Qura University, Makkah.

[13] Smith, T. (2009). The social media revolution. International journal of market research, 51(4), 559-561.

[14] Wong, K., Wang, F. L., Ng, K. K., \& Kwan, R. (2015). Investigating acceptance towards mobile learning in higher education students. In Technology in Education. Transforming Educational Practices with Technology (pp. 9-19). Springer Berlin Heidelberg.

[15] Xodabande, I. (2017). The effectiveness of social media network telegram in teaching English language pronunciation to Iranian EFL learners. Cogent education, 4(1), 1347081.

[16] Zarei, R., Heidari Darani, L., \& Ameri-Golestan, A. (2017). Effect of Telegram Application on Iranian Advanced EFL Learners' Vocabulary Knowledge and Attitude. International Journal of Foreign Language Teaching and Research, 5(20), 96109.

Muntaha Ali Mohammad Al Momani was born in Irbid city in Jordan on 16th of December 1979. She received her B.A in English for Specific Purposes from Jordan university of Science and Technology in 2001, and M.D in English Teaching Methods from Al-hashimia university in 2005.

She is an instructor in Al-Balqa Applied University, Ajloun University College, Department of English. She taught Mandatory courses as English (099), English (101), and English (102), moreover she taught skills like writing, reading, and speaking.

Here research focuses on the "Effectiveness of social media application telegram messenger in improving students reading skills" 